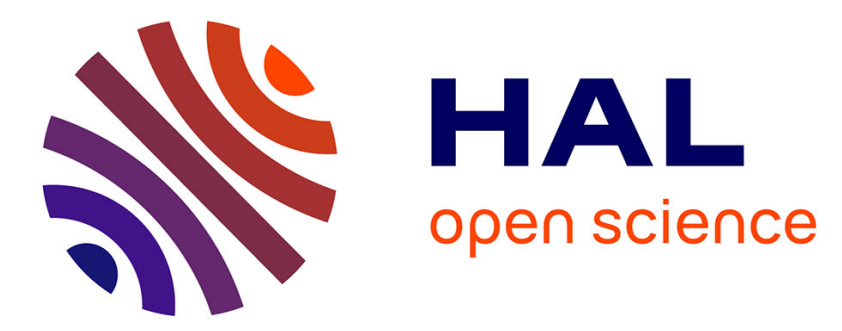

\title{
Improvement of ventilation homogeneity in an industrial batch-type carcass chiller by CFD investigation
}

Pierre-Sylvain Mirade, Laurent Picgirard

\section{To cite this version:}

Pierre-Sylvain Mirade, Laurent Picgirard. Improvement of ventilation homogeneity in an industrial batch-type carcass chiller by CFD investigation. Food Research International, 2006, 39 (8), pp.871881. 10.1016/j.foodres.2006.05.002 . hal-02666941

\section{HAL Id: hal-02666941 https://hal.inrae.fr/hal-02666941}

Submitted on 31 May 2020

HAL is a multi-disciplinary open access archive for the deposit and dissemination of scientific research documents, whether they are published or not. The documents may come from teaching and research institutions in France or abroad, or from public or private research centers.
L'archive ouverte pluridisciplinaire $\mathbf{H A L}$, est destinée au dépôt et à la diffusion de documents scientifiques de niveau recherche, publiés ou non, émanant des établissements d'enseignement et de recherche français ou étrangers, des laboratoires publics ou privés. 


\title{
Improvement of ventilation homogeneity in an industrial batch-type carcass chiller by CFD investigation
}

\author{
Pierre-Sylvain Mirade ${ }^{\mathrm{a}, *}$, Laurent Picgirard ${ }^{\mathrm{b}}$ \\ ${ }^{a}$ Equipe Couplage Transferts-Transformations (C2T), Unité Qualité des Produits Animaux (QuaPA), \\ Institut National de la Recherche Agronomique (INRA), Theix, 63122 St Genès Champanelle, France \\ ${ }^{\mathrm{b}}$ Association pour le Développement de l'Institut de la Viande (ADIV), 2 rue Chappe, 63039 Clermont-Ferrand, France
}

Received 23 January 2006; accepted 12 May 2006

\begin{abstract}
This paper discusses the application of a computational fluid dynamics (CFD) approach, first to predict air velocities in an industrial batch-type carcass chiller, and second to designing low-cost technical solutions to improve ventilation homogeneity around the carcasses. Comparisons between calculations and measurements revealed close agreement in the qualitative prediction and some inaccuracies in the quantitative prediction of airflow velocities in both the current and the modified chiller configurations. Adding deflectors at the air-conditioning blower outlet and a plastic wall behind the last row led to a marked improvement in ventilation homogeneity within the plant by both reducing the standard deviation of airflow velocities onto each row and improving airflow velocity onto the last row. Compared with the experiments, CFD is therefore a low-cost option well suited to testing new technical solutions designed for improving the operation of food plants.
\end{abstract}

(C) 2006 Elsevier Ltd. All rights reserved.

Keywords: Ventilation homogeneity; Air velocity; CFD; Carcass chiller; Deflectors

\section{Introduction}

The performance of carcass chillers is known to be affected by airflow distribution, just as much in batch-type systems as continuous-type systems. In batch chillers, the spatial heterogeneity of air velocity is the main source of variations in chilling times and weight losses, which are the two most important economic criteria for process efficiency and homogeneity. Wooton (1986) studied the relative effect of various parameters (carcass location, carcass weight, fatness, grade and time of entry into the plant, etc.) on deep leg temperature in beef carcasses chilled in a conventional batch plant. He highlighted variations of over $10^{\circ} \mathrm{C}$ in the temperatures reached at $24 \mathrm{~h}$ after slaughter. A multivariate analysis showed that carcass location

\footnotetext{
${ }^{*}$ Corresponding author. Fax: +33 473624089.

E-mail address: mirade@clermont.inra.fr (P.-S. Mirade).
}

(i.e. air velocity distribution) in the room was as important as carcass weight in explaining the observed temperature heterogeneity. Kondjoyan and Daudin (1997a) calculated that the core temperature and weight losses of $80 \mathrm{~kg}$ pork carcasses varied from $1.7^{\circ} \mathrm{C}$ to nearly $11^{\circ} \mathrm{C}$ and from $1.8 \%$ to $2.8 \%$, respectively, depending on whether the carcasses were located close to a fan refrigerator unit where the airflow velocity, temperature and turbulence reached $2.0 \mathrm{~m} \mathrm{~s}^{-1},-1{ }^{\circ} \mathrm{C}$ and $40 \%$, respectively, or whether they were located in a poorly ventilated area where air velocity, temperature and turbulence reached $0.5 \mathrm{~m} \mathrm{~s}^{-1}, 3{ }^{\circ} \mathrm{C}$ and $6 \%$. In continuous chillers, although the movement of each carcass means average air velocity remains the same, the existence of poorly ventilated areas is much more harmful to process efficiency than airflow heterogeneity because potentially large areas are liable to strongly and durably alter the chilling kinetics (Daudin \& Van Gerwen, 1996). Mirade, Kondjoyan, and Daudin (2002) calculated that increasing the ventilation level in a continuous-type chiller 
from a mean velocity of $0.17 \mathrm{~m} \mathrm{~s}^{-1}$ (with variations ranging from 0.10 to $0.45 \mathrm{~m} \mathrm{~s}^{-1}$ ) to $0.39 \mathrm{~m} \mathrm{~s}^{-1}$ (with variations ranging from 0.10 to $1.02 \mathrm{~m} \mathrm{~s}^{-1}$ ) led to a $14 \%$ increase in the heat extracted from an $80 \mathrm{~kg}$ pork carcass. These authors also indicated that this change in ventilation level shortened the chilling time of the carcass by only $20 \mathrm{~min}$, while increasing its total weight loss from $1.3 \%$ to $1.7 \%$. However, as affirmed by Mirade and Picgirard (2001), there can be no ideal chiller design and operation, since each configuration, whether batch-type or continuous, suffers from specific disadvantages leading to airflow heterogeneity (which impairs process efficiency) caused by both air-conditioning system and plant geometry.

Until now, engineers have used practical know-how and rules of thumb in chiller design and operation, with all the inherent risks of making mistakes. However, Computational Fluid Dynamics (CFD) codes are now commercially available, and over the last ten years, many authors since the original studies performed by Van Gerwen and Van Oort (1989) and Wang and Touber (1990) have investigated the use of CFD as a tool for rationalizing design and operation (Foster, Barrett, James, \& Swain, 2002; Hoang, Verboven, De Baerdemaeker, \& Nicolaï, 2000; $\mathrm{Hu} \&$ Sun, 2000; Mariotti, Rech, \& Romagnoni, 1995; Mirade, Daudin, \& Arnaud, 1995; Mirade \& Daudin, 1998a; Mirade et al., 2002; Scott, 1994; Scott \& Richardson, 1997; Xia \& Sun, 2002; Xie, Qu, Shi, \& Sun, 2006). General purpose CFD codes such as Fluent, CFX, Star$\mathrm{CD}$ and Phoenics have been designed for solving turbulent fluid flow problems coupled with heat and mass transfers in a given geometry by the use of a mesh where all the Navier-Stokes transport equations are solved across each mesh cell by means of an iterative procedure requiring specific algorithms. The above-mentioned studies highlight how the application of CFD will improve our understanding of the dynamics and physics of the chilling operation and thus help to optimize existing equipment and design new solutions. Mirade and Picgirard (2001) used CFD techniques to improve air circulation around beef carcasses in a continuous-type chiller. Based on two-dimensional models, they showed that installing a jet deflector in front of the fans of the cooling batteries offered a good compromise between efficiency in terms of airflow patterns and investment costs, without experimentally checking the beneficial effects of adding this deflector.

A similar approach was used in this study to improve airflow distribution inside a $348 \mathrm{~m}^{3}$ batch-type meat carcass chiller where measurements had pointed to a lack of ventilation homogeneity. Two types of three-dimensional CFD model were constructed; the first designed to match calculated air velocities with measurements in order to fit the parameters of the porous media used to represent the rows of carcasses, while the second type was designed to identify technical solutions offering significant improvements in ventilation homogeneity around the carcasses. The better technical solutions, i.e. those which led to a more homogeneous airflow distribution while lowering investment costs, were then installed, and their efficiency in terms of improved ventilation homogeneity was assessed and compared to the numerical results obtained beforehand.

\section{Materials and methods}

\subsection{Chiller description and air velocity measurements}

The batch-type meat carcass chiller used in this study is illustrated in Fig. 1a (longitudinal section) and b (top view). The chiller was $11.45 \mathrm{~m}$ long, $7.7 \mathrm{~m}$ wide and $3.95 \mathrm{~m}$ high, giving an overall volume of $348 \mathrm{~m}^{3}$. The full airflow rate blown into the plant was $5.64 \mathrm{~m}^{3} \mathrm{~s}^{-1}$ $\left(20,300 \mathrm{~m}^{3} \mathrm{~h}^{-1}\right)$, i.e. an air change rate of about 58 volumes $\mathrm{h}^{-1}$. The filling capacity of this small carcass chiller was 66 beef carcasses arranged in nine rows, or more when multiple species carcasses are chilled at the same time (Fig. 1a). The air-conditioning system was composed of a cooling battery coupled with helicoidal fans placed at one end and at half-width of the chiller (Fig. 1a and b). Air was extracted through a $0.65 \mathrm{~m}$-high $2.27 \mathrm{~m}$-wide opening set $0.5 \mathrm{~m}$ from the floor, then conditioned and blown through another opening $0.37 \mathrm{~m}$ high and $2.15 \mathrm{~m}$ wide set $3.25 \mathrm{~m}$ from the floor. The first row of carcasses was located at $0.60 \mathrm{~m}$ from the air conditioning system. Distance between two consecutive rows was $1.0 \mathrm{~m}$, and the ninth row was $1.9 \mathrm{~m}$ away from the wall of the plant.

An experimental study of air velocity carried out in the chiller yielded a diagnosis of its overall operation (Picgirard \& Mirade, 2005). This diagnosis was obtained using a method specially developed for measuring velocity by means of a hot-film anemometer in an industrial air flow (Mirade \& Daudin, 1998b). This method allows the average values of air velocity to be quickly and accurately calculated at up to several thousand points via the following procedure: (i) probes are moved slowly and continuously, and measurements are recorded at regular intervals; (ii) a signal processing technique is applied to the data to eliminate time variations due to airflow unsteadiness as far as possible, and thus obtain mean air velocity values versus spatial co-ordinates. Measurement accuracy is $0.1 \mathrm{~m} \mathrm{~s}^{-1}$, i.e. equal to the measurement error when using a hot-film anemometer. In addition, this method reduces experiment duration 350-fold compared with the standard procedure which consists in averaging measurements over a long enough time to obtain a constant value for mean velocity (Mirade \& Daudin, 1998b).

Owing to the batch operating conditions of the chiller investigated in this study, a purpose-built cableway-type system (Mirade \& Picgirard, 2001) was used to support the measurement devices and automatically move them at a slow and fairly constant velocity. The measurement devices were multi-directional hot-film anemometers (model 8465, TSI, St. Paul, USA) connected to a data-logger (Squirrel 1000, Grant, Cambridge, England). A travel velocity of about $0.017 \mathrm{~m} \mathrm{~s}^{-1}$ was chosen for the experi- 


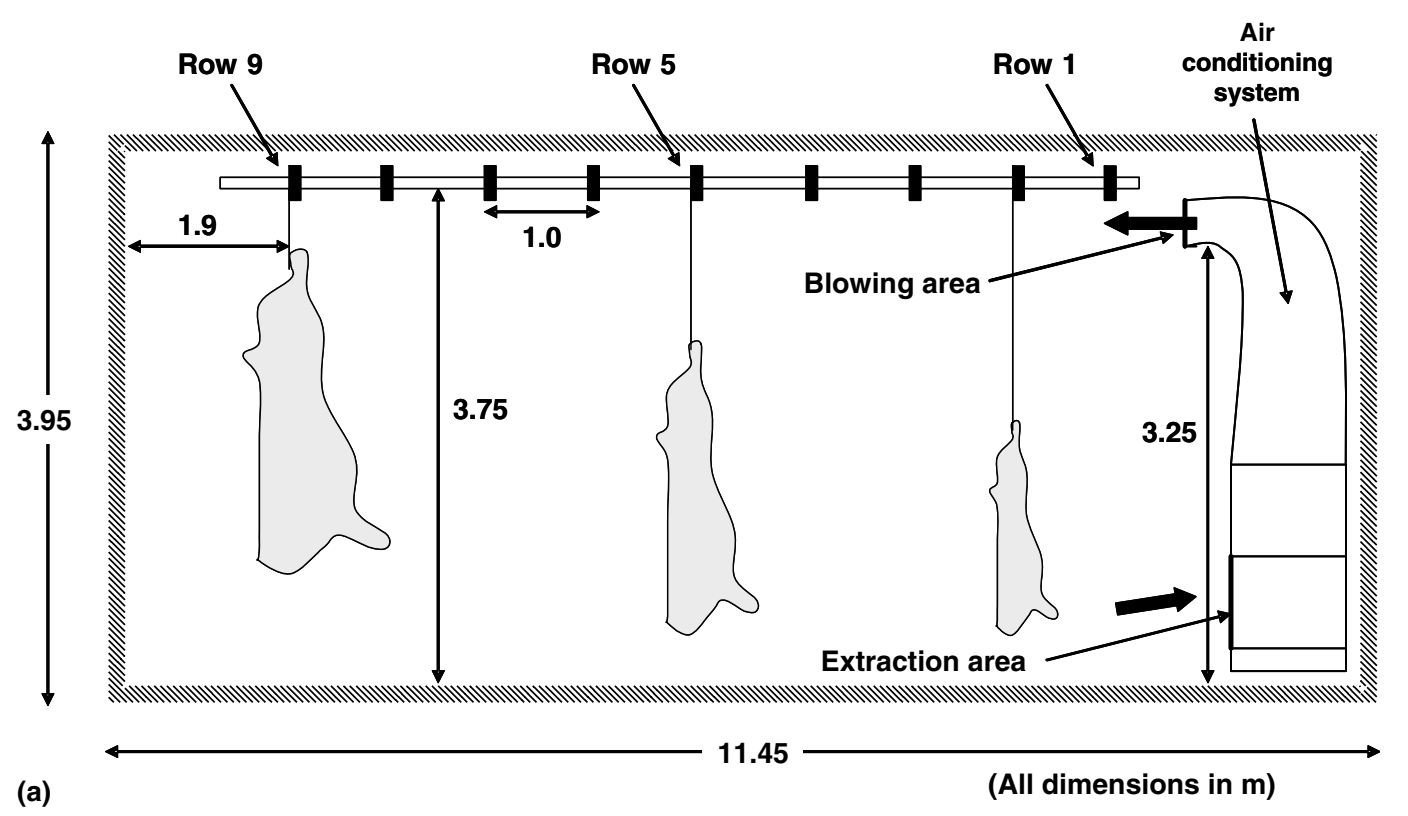

(a)

(All dimensions in $\mathrm{m}$ )

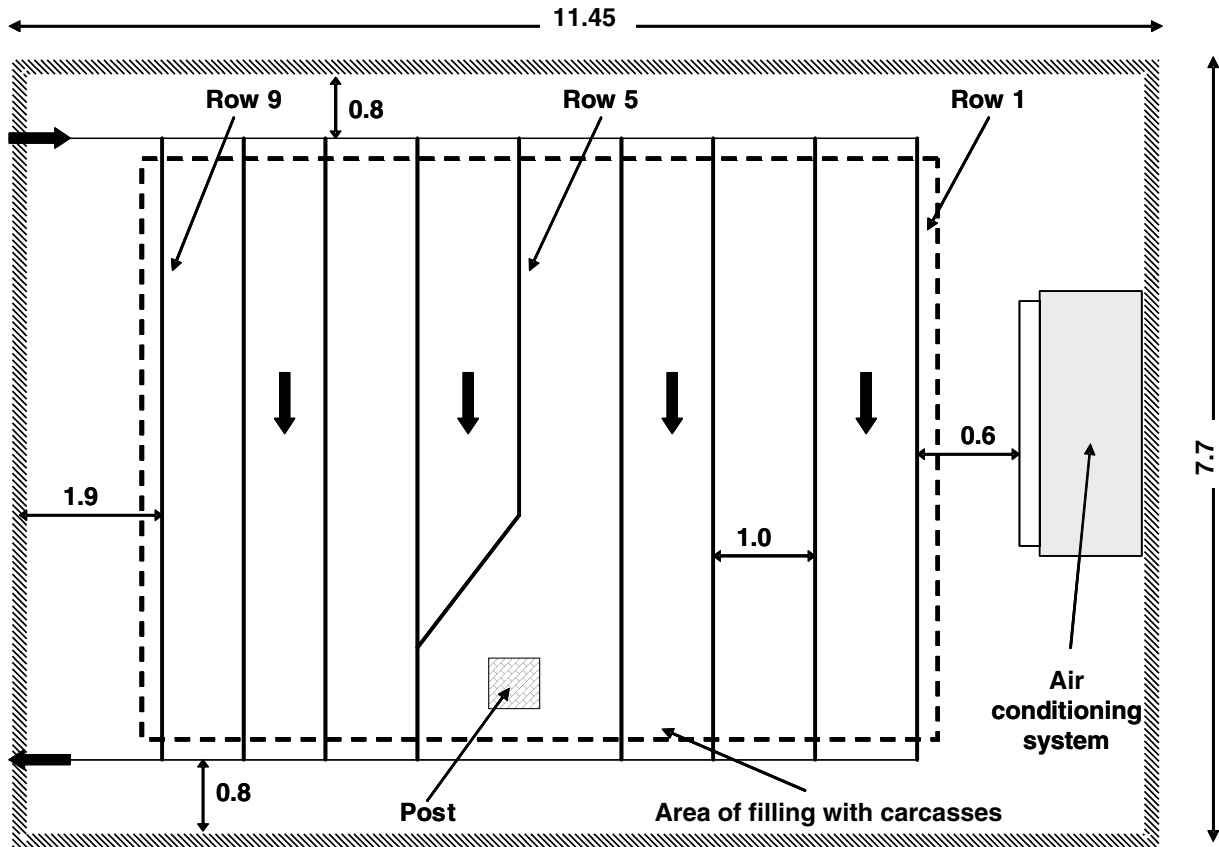

(b)

(All dimensions in $\mathrm{m}$ )

Fig. 1. Illustration of the geometry of the current configuration of the industrial batch-type carcass chiller studied in this work: (a) a longitudinal section and (b) a top view. The arrows represent either the air inflow and outflow (a) or the movement direction of the meat carcasses when filling and emptying the chiller (b).

ments, since it is high enough to keep the experimental time short but low enough to be negligible compared with the air velocity to be measured.

\subsection{Computational fluid dynamics models}

Based on the geometrical configuration presented in Fig. 1, we used the CFD code 'Fluent 6.0.20' (Anonymous, 2001) to build two series of numerical models based on unstructured three-dimensional hybrid meshes of
911,500-2,732,000 hexahedral and tetrahedral cells. The inside of the air-conditioning system was considered as being outside the computational domain, therefore air inflow corresponded to the output from the opening located at $3.25 \mathrm{~m}$ from the floor, and air outflow corresponded to the opening located in the lower part of the air conditioning system.

To simplify the meshes and thus reduce total computation time, each of the nine rows of carcasses was represented by an anisotropic mega-porous medium coupled 
with the Darcy-Forchheimer approach in which viscous resistance, inertial resistance and porosity factors had to be adjusted according to the three spatial directions. Due to the absence of a rational method for calculating these factors, the first series of models was constructed to identify them by visually comparing the measured fields with the air velocity fields determined from a host of CFD calculations, by assuming that the viscous resistance factor was equal to zero whatever the considered spatial direction. This assumption amounts to neglecting the Darcy term in comparison with the Forchheimer term in the expression of the momentum source term added to the standard fluid flow equations. In other words, it means that the mean static pressure gradient is linear with the squared mean air velocity within the porous medium, and not proportional to the velocity as expressed by the Darcy formulation. This assumption is often made in bioclimatology when assessing airflows in greenhouses or wind circulation in forests (Bartzanas, Boulard, \& Kittas, 2002) and was recently verified in a food industry setting (Mirade, Agabriel, Brunet, $\&$ Boulard, 2004). Further to the analysis of 25 simulations, porosity factor was determined as $90 \%$ whatever the considered spatial direction, and values of 50,2 and $5 \mathrm{~m}^{-1}$ were determined for the inertial resistance factors according to length of the rows (width of the room), vertical direction and width of the rows (length of the room), respectively. These factor values were assumed to be mean values and thus constant for any row of carcasses, i.e. regardless of animal species, size of the carcass and row fill rate.

Once the factors of the porous medium formulation were determined, a second series of $643 \mathrm{D}$ simulations was performed to identify efficient technical solutions for improving ventilation homogeneity within the carcass chiller. All these solutions were based on adding deflectors, either level with the ceiling to force the air to penetrate through the rows of carcasses or added directly at the air-conditioning blower outlet to better channel the airflow towards the carcasses. The aim of these new simulations was to optimize the number, dimensions, location and orientation of these deflectors, while assessing the improvement in ventilation homogeneity around the carcasses.

In all the numerical models built, airflow was considered as steady, incompressible, isothermal and turbulent. Main flow turbulence was taken into account using the triedand-tested standard k- $\varepsilon$ model (Launder \& Spalding, 1972) when far from the walls, which were assumed to be smooth, and where the standard wall function was applied. The Simple algorithm (Patankar \& Spalding, 1972) was chosen for coupling pressure and velocity and introducing pressure into the continuity equation. A first-order upwind differencing scheme was incorporated into the computational models as discretization scheme for the convection terms of each governing equation. First-order schemes are known to increase numerical diffusion due to discretization errors, especially when the flow is not aligned with the mesh, i.e. for triangular and tetrahedral grids (Hirsch,
1988). Although they therefore yield less accurate results, first-order schemes give better convergence of calculation than second-order schemes.

For all the calculations performed, an air velocity of $7.1 \mathrm{~m} \mathrm{~s}^{-1}$ determined from the total airflow rate into the chiller and a turbulence rate arbitrarily valued at $20 \%$ were specified in the inlet area corresponding to the area of the opening located at $3.25 \mathrm{~m}$ from the floor. An outflow-type boundary condition was applied at the extraction area located in the lower part of the air-conditioning system at $0.5 \mathrm{~m}$ from the floor. This type of condition is conventionally used when details on air velocity and pressure fields are unknown prior to solution of the flow problem; it is obeyed in fully developed flows where the diffusion flux for all variables in the exit direction is zero.

Calculations were performed on a $3 \mathrm{GHz}$ Pentium IV computer with $2 \mathrm{~Gb}$ of RAM. Computation time ranged from about $8.5-17 \mathrm{~h}$ depending on the number of the cells in the numerical models, which varied from 911,500 to $2,732,000$.

\section{Results and discussion}

Given the large number of simulations performed to calculate airflow patterns in the existing configuration (and also to fit the porous media factors), and to test technical solutions liable to improve ventilation homogeneity, only significant results are reported here, i.e. results corresponding to the existing configuration with porous media porosity and inertial resistance factors fitted to $90 \%, 50,2$ and $5 \mathrm{~m}^{-1}$, respectively, and results corresponding to the technical solutions that most significantly reduced the heterogeneity of the air velocity distribution.

\subsection{Air velocity fields corresponding to the existing configuration of the chiller}

The numerical results for the existing chiller configuration indicated a fairly strong heterogeneous airflow, i.e. air velocities above $1.8 \mathrm{~m} \mathrm{~s}^{-1}$ in the upper half (Fig. 2) resulting from the air jet blown by the air-conditioning blowing outlet that follows the ceiling. According to Fig. 2, rows 2-5 filled with small-sized carcasses and the lower half of the four following rows were not sufficiently ventilated, with large areas exposed to air velocities of $0.3 \mathrm{~m} \mathrm{~s}^{-1}$ or less. Only row 1 seemed to be correctly ventilated, almost certainly due to the presence of the extraction area located nearby. As shown in Fig. 2, at half-width of this batch chiller, the air blown by the air-conditioning system mainly follows the ceiling above the first five rows of carcasses before going down beyond the ninth row against the wall and travelling back to the extraction area.

Fig. 3, which is a top view located at a height of $3.1 \mathrm{~m}$, confirms the jet effect caused by the air-conditioning blowing outlet as highlighted by the previous figure. Fig. 3 also shows that, outside the well-ventilated area resulting from the jet effect, ventilation is poor, with air velocities below 




\subsection{0 \\ 150}

1.50

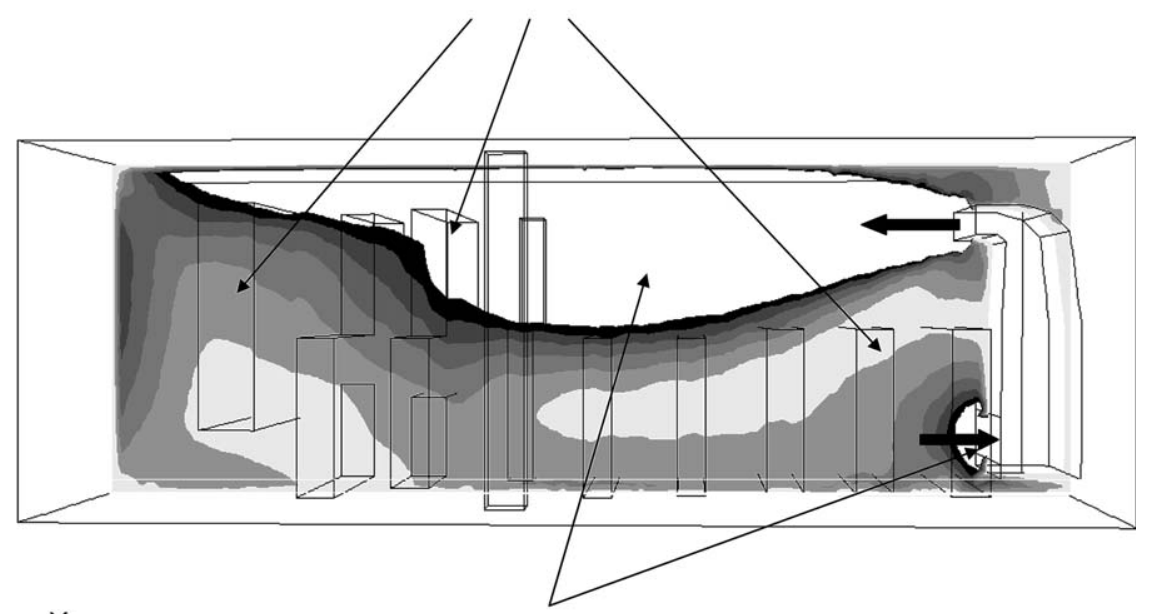

0.30

0.00

$z-x$

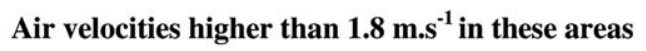

Fig. 2. Air velocity fields calculated on a longitudinal section located at half-width in the current configuration of the batch-type chiller. The two arrows represent air inflow and air outflow.

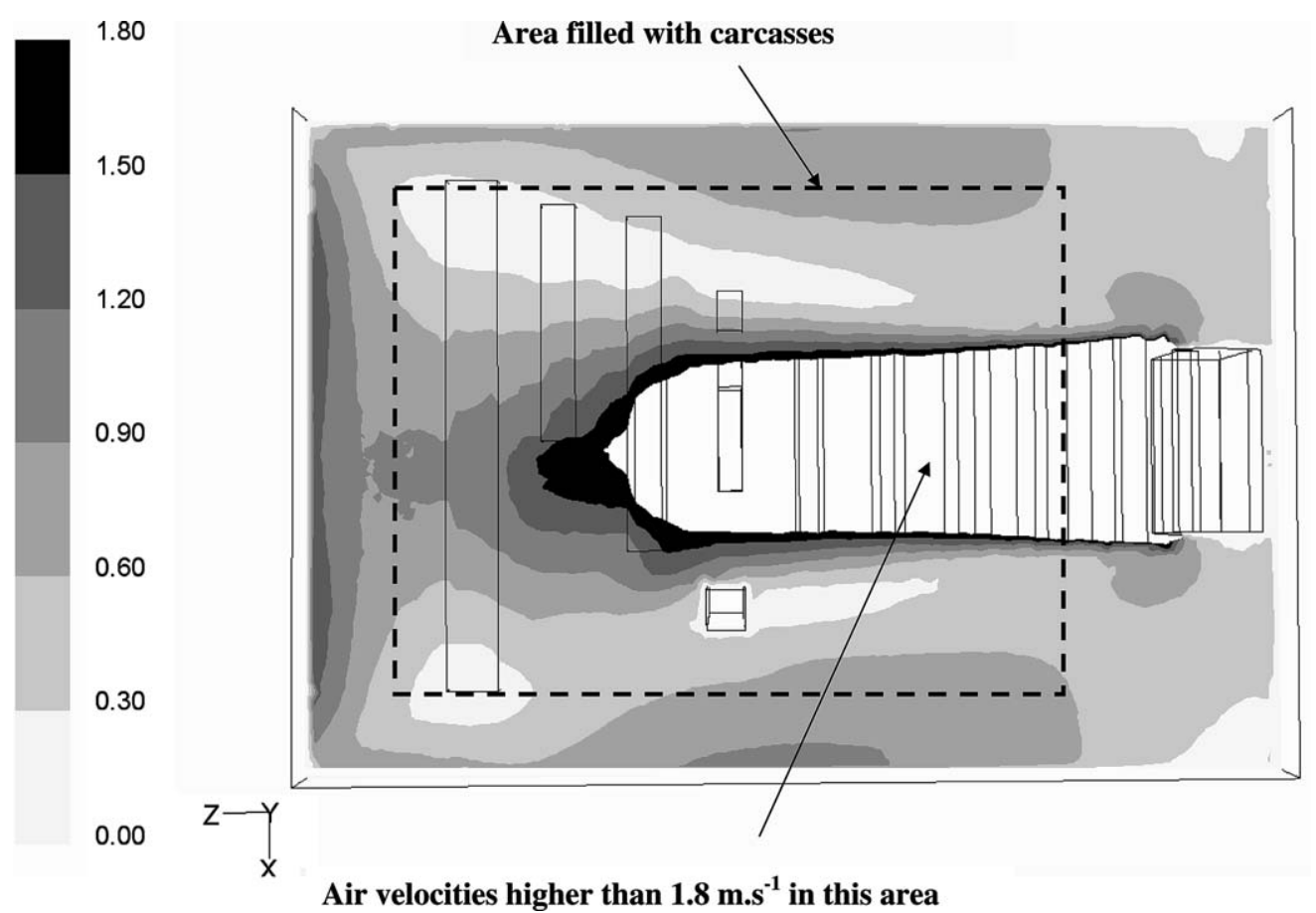

Fig. 3. Air velocity fields calculated on a horizontal section located at a height of $3.1 \mathrm{~m}$ from the floor in the current configuration of the carcass chiller.

$0.6 \mathrm{~m} \mathrm{~s}^{-1}$ in the area filled by the carcasses. Finally, Figs. 2 and 3 show a marked jet effect, leading to a highly ventilated area facing the air-conditioning blowing outlet, with areas exposed to much lower air velocities everywhere else. This uneven ventilation distribution almost certainly causes variation in chilling times, since beef carcasses that are generally placed in row 9, namely in a low-velocity area, will cool far more slowly than carcasses of lower weight placed elsewhere. Kondjoyan and Daudin (1997a) calculated that a variation of the air velocity from 0.5 to $1.5 \mathrm{~m} \mathrm{~s}^{-1}$ shortened the chilling time by $21 \%$ for a cylinder $0.05 \mathrm{~m}$ in diameter, and by $7 \%$ for a cylinder $0.3 \mathrm{~m}$ in diameter. From data obtained on real beef carcasses, James and Bailey (1989) arrived at similar conclusions about the effect of air velocity on beef chilling. Turbulence intensity is also an important parameter in explaining variation on chilling times of 
carcasses since heat transfer coefficients increase by $50 \%$ at the surface of a pork hindquarter, when turbulence intensity varies from $1.3 \%$ to $30 \%$ (Kondjoyan \& Daudin, 1997b). However, this parameter remains impossible to accurately calculate from a CFD modelling in view of the memory size available on the computers that are currently used.

Comparisons performed between the numerical predictions of air velocities and the 784 measurement points in the batch chiller revealed quite close agreement and correlation between the two, as revealed by the slope of 0.86 and the coefficient $R^{2}$ of 0.81 of the straight line linking velocity prediction and measurement (Fig. 4a). However, the CFD model underestimated the air ventilation levels since the slope is not equal to the ideal value 1 . However, the jet effect facing the blowing area that leads to air velocities ranging from about 2 to $5 \mathrm{~m} \mathrm{~s}^{-1}$ seems to have been be correctly predicted (Fig. 4a).
Fig. $4 \mathrm{~b}$ that compares air velocity prediction versus carcass row number shows that the poor performance of the CFD model is particularly obvious beyond row 6; in this part of the chiller, the underestimated prediction of air velocity reached $29 \%$ for row $7,37 \%$ for row 8 and exceeded $40 \%$ for the last row of carcasses. Unlike the three last rows of carcasses, the CFD model built thus overestimated the ventilation level in row 1 (located in front of the extraction area of the air conditioning system) by over $36 \%$ (Fig. 4b). For rows 2-6, the discrepancy between calculated and measured air velocities ranged from less than $1 \%$ (row 2 ) to about $17 \%$ (row 4 ), and remained lower than the discrepancies commonly reported in three-dimensional airflow pattern modelling studies in cooling plants (Hoang et al., 2000; Mirade \& Daudin, 1998a).

Several possible solutions may be put forward to improve the limited accuracy in air velocity prediction
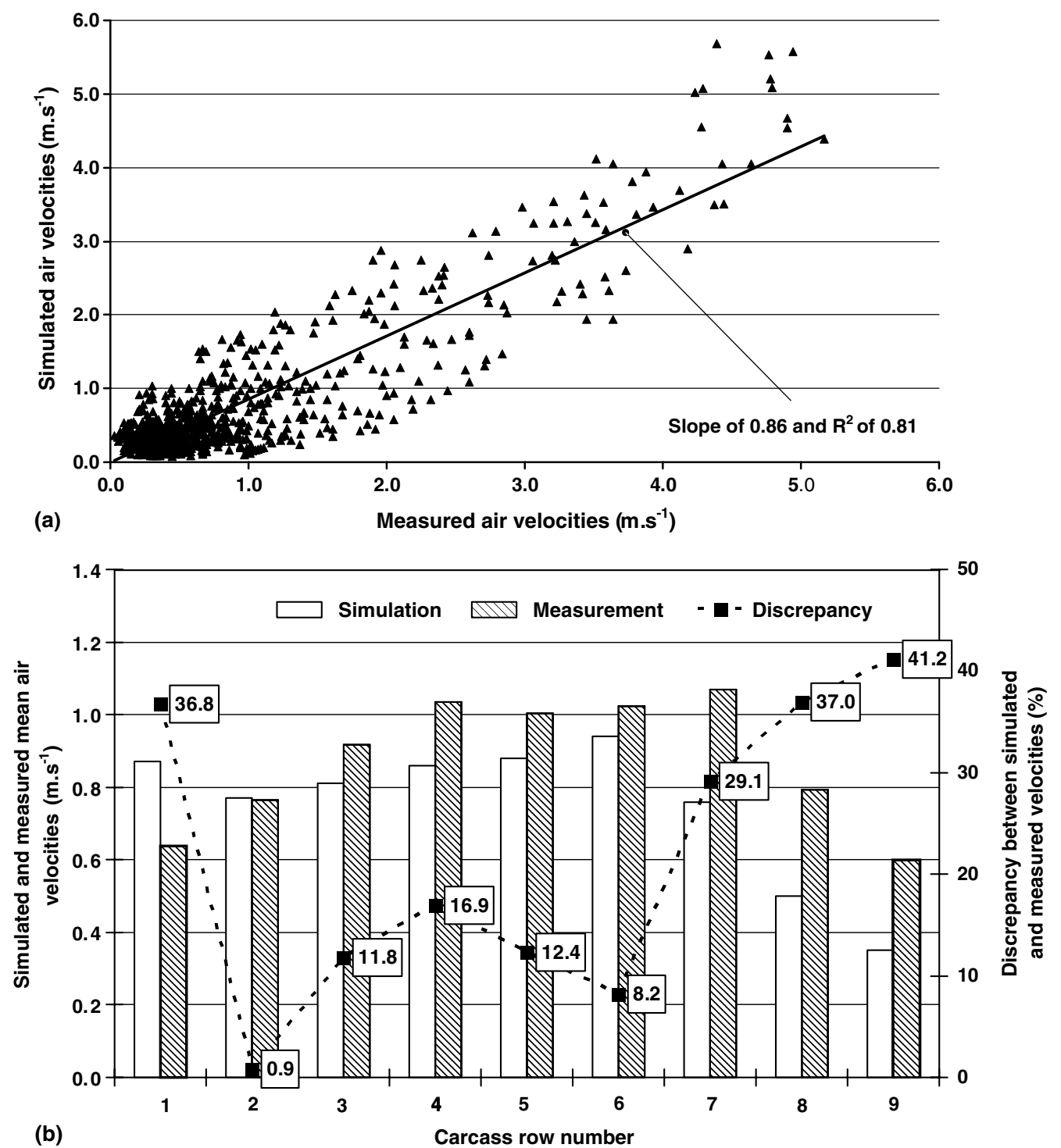

Fig. 4. Comparison between simulated and measured air velocities in the existing chiller configuration: (a) overall comparison and (b) versus carcass row number. 
for rows 1, 7-9: (i) the integration into the CFD model of the Reynolds-stress model for modelling turbulence and of a second-order differencing scheme as discretization scheme for the convections terms in the fluid mechanics equations since the standard $\mathrm{k}-\varepsilon$ model and the first-order upwind differencing scheme are known to reduce strong gradients and give rise to numerical diffusion (Hirsch, 1988) and (ii) the use of a finer mesh to obtain truly independent results. Furthermore, the use of porous media which only roughly describe the preferential paths for airflow over the meat carcasses into the rows certainly impaired the accuracy of the numerical model. However, a compromise had to be found between the accuracy of the results and the computation time; consequently, the standard $\mathrm{k}-\varepsilon$ model, the first-order upwind differencing scheme, a porous media modelling, together with a mesh having 911,500 cells were used.
Given the sufficient accuracy in the air velocities predictions for the current configuration, the CFD code 'Fluent' (Anonymous, 2001) was then applied in attempt to design technical solutions for reducing ventilation heterogeneity inside the batch chiller.

\subsection{Air velocity fields corresponding to the modified configurations of the chiller}

As mentioned earlier, the second series of $3 \mathrm{D}$ simulations was performed to identify efficient and low-cost technical solutions that significantly improve ventilation homogeneity. All these solutions were based on adding deflectors either level with the ceiling, in order to force the air to penetrate through the rows of carcasses, or directly at the air-conditioning blowing outlet in order to better channel airflow towards the carcasses. The aim of

(a)

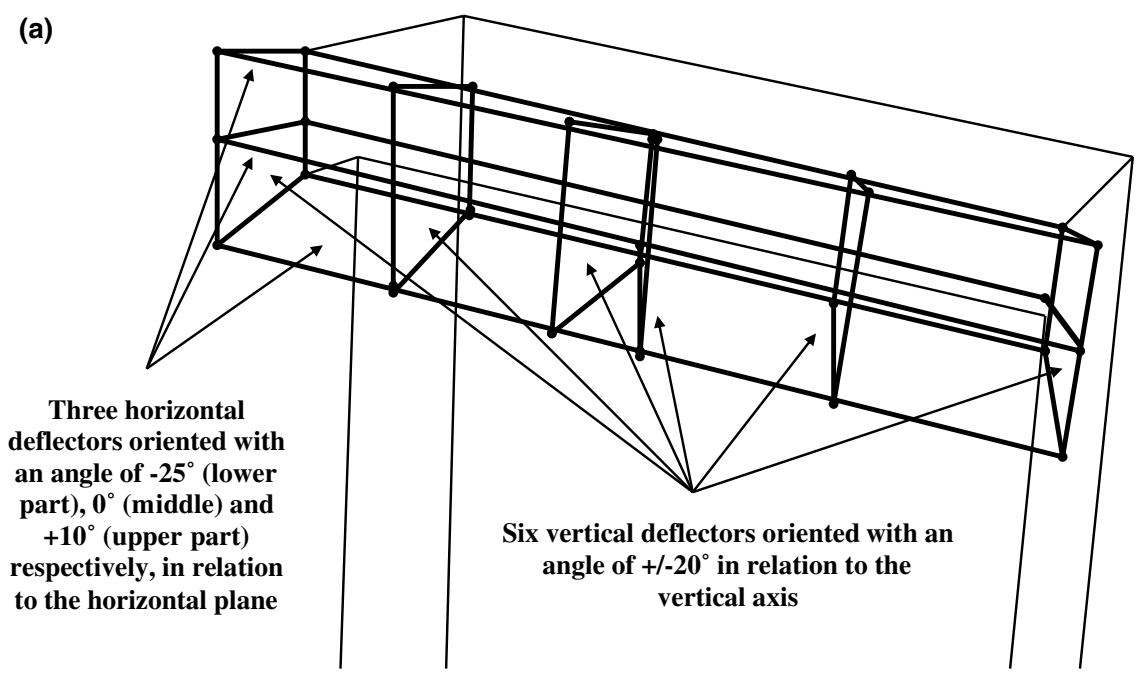

(b)



Fig. 5. Schematic description of the geometry changes performed in the chiller and designed in response to CFD investigations in order to improve ventilation homogeneity around the carcasses, namely: (a) adding of a set of deflectors just at the output of the blowing area of the air conditioning system and (b) adding of plastic walls around row 9. 
the second series of simulations was to optimize the number, dimensions, location and orientation of these deflectors, while assessing the improvement in ventilation homogeneity around the carcasses.
Fig. 5 details a set of low-cost solutions that most improved air velocity homogeneity around the carcasses. These solutions, which can be easily implemented inside the batch chiller, consist in adding three horizontal and
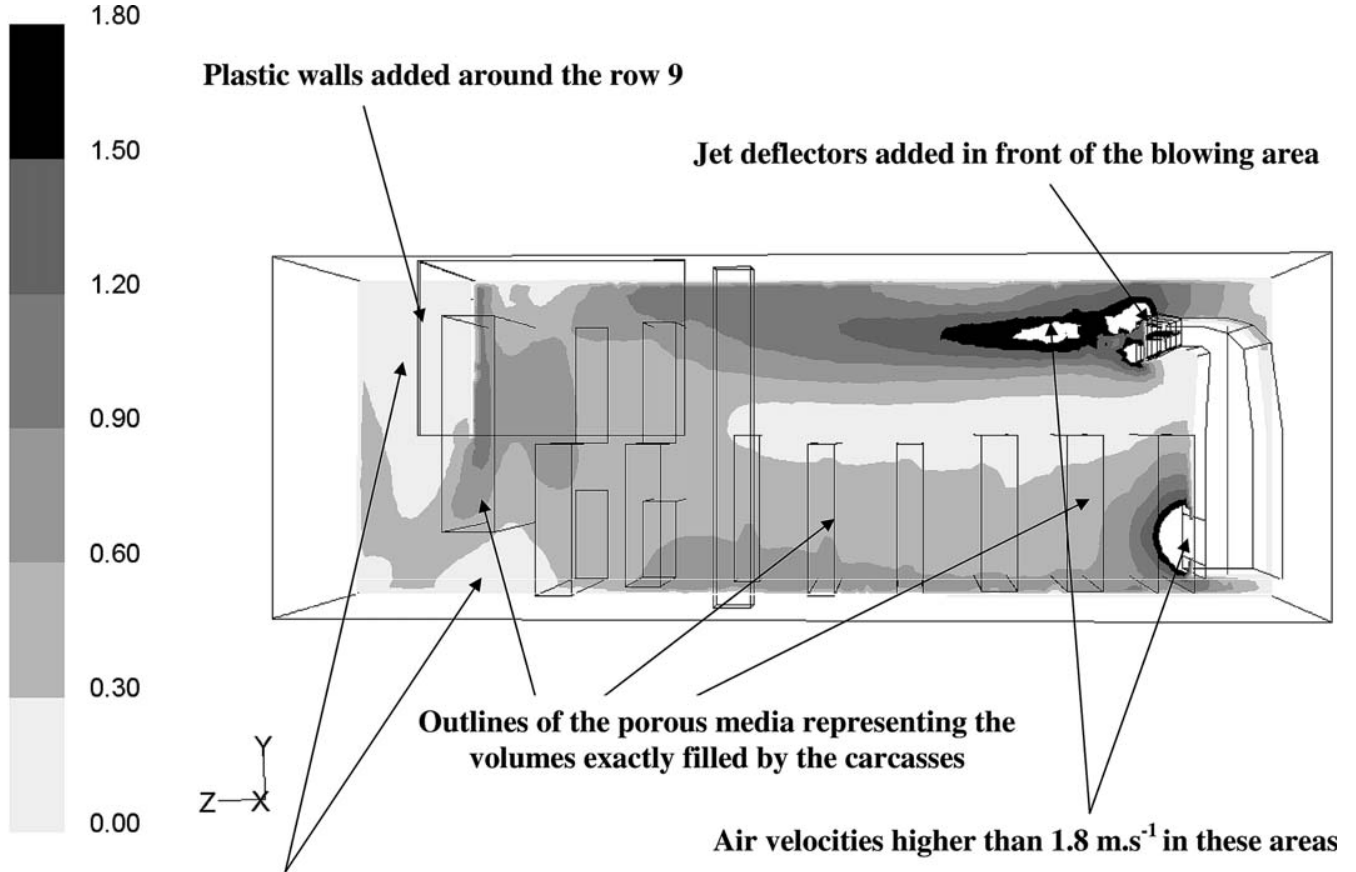

\section{Air velocities lower than $0.3 \mathrm{~m} . \mathrm{s}^{-1}$ in these areas}

Fig. 6. Air velocity fields calculated on a longitudinal section located at half-width in the configuration of the batch-type chiller in which the set of deflectors and three plastic walls were added in front of the air-conditioning blower outlet and behind row 9 , respectively.

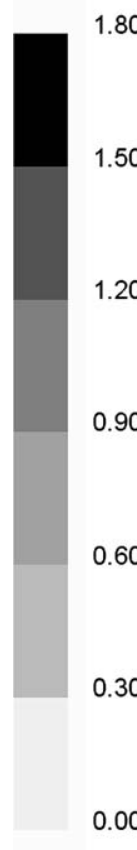

Plastic walls added around the row 9

\section{Jet deflectors}

1.50
1.20
0.90
0.60

0.00

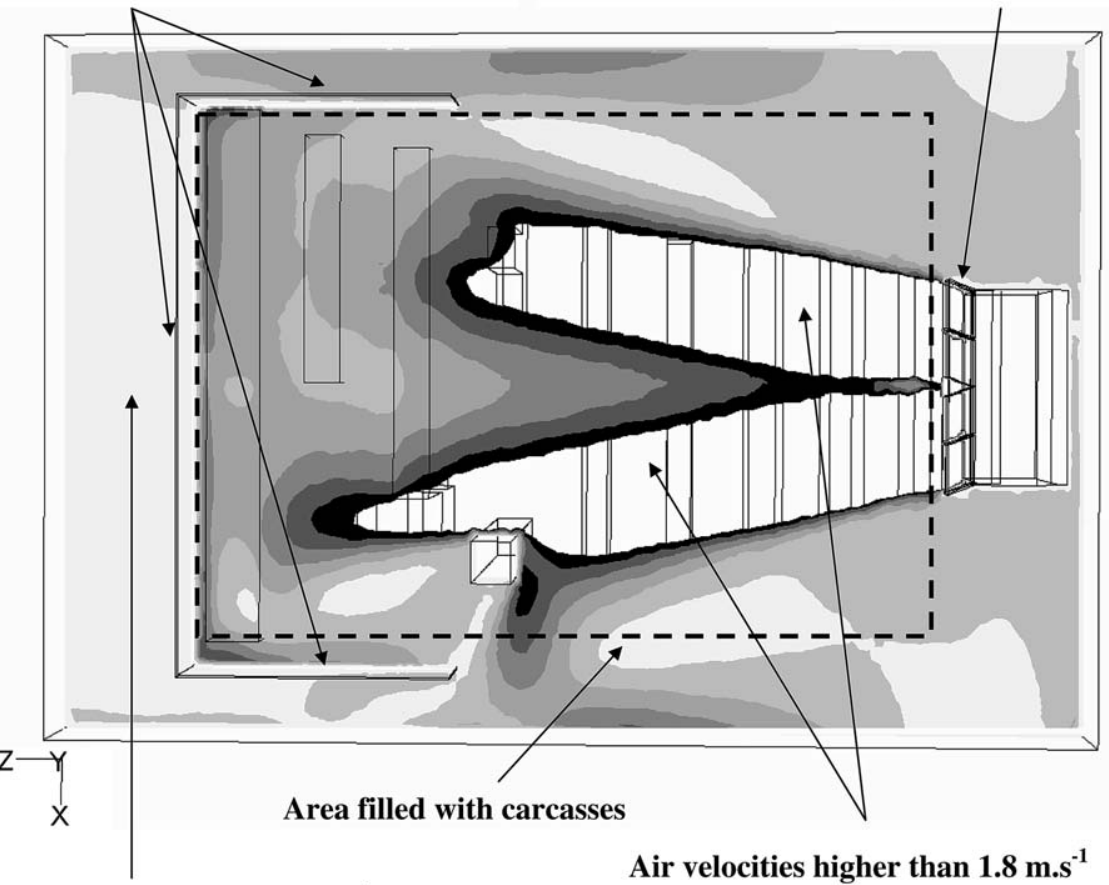

Air velocities lower than $0.3 \mathrm{~m} . \mathrm{s}^{-1}$

Fig. 7. Air velocity fields calculated on a horizontal section located at a height of $3.1 \mathrm{~m}$ from the floor in the carcass chiller configuration in which the set of deflectors and three plastic walls were added in front of the air-conditioning blower outlet and behind row 9 , respectively. 
six vertical jet deflectors immediately at the output of the blowing area (Fig. 5a), and surrounding the ninth row of carcasses with $1.95 \mathrm{~m}$ long plastic walls going down from the ceiling to $2 \mathrm{~m}$ from the floor (Fig. $5 \mathrm{~b}$ ).

A comparison of Fig. 6 with Fig. 2 shows that the addition of jet deflectors in front of the blowing area coupled with plastic walls around row 9 significantly reduces the heterogeneity in airflow distribution between the upper half and lower half of the chiller as well as beyond row 6 . The large area with air velocities higher than $1.8 \mathrm{~m} \mathrm{~s}^{-1}$ that is visible in Fig. 2 has almost disappeared in Fig. 6, presumably on account of the installation of the vertical deflectors that were oriented with an angle of $\pm 20^{\circ}$ in relation to the vertical axis so that a large part of the air blown by the air- conditioning system flowed towards the sides of the rows. The lower part of the chiller seems to be ventilated in a more homogeneous way as a result of adding the three horizontal deflectors at the outlet of the blowing opening. Fig. 6 also seems to indicate that surrounding the ninth row with plastic walls gives rise to higher air velocities around the carcasses filling rows 8 and 9 compared with the existing configuration (Fig. 2), since the area with air velocities lower than $0.3 \mathrm{~m} \mathrm{~s}^{-1}$ has clearly decreased in size.

Fig. 7 clearly illustrates the effect of the six vertical deflectors placed in front of the blowing area. The air jet leading to the highly ventilated area facing the blower outlet, and which is visible in Fig. 3, is separated into two parts because of the $\pm 20^{\circ}$ orientation of the vertical deflectors,
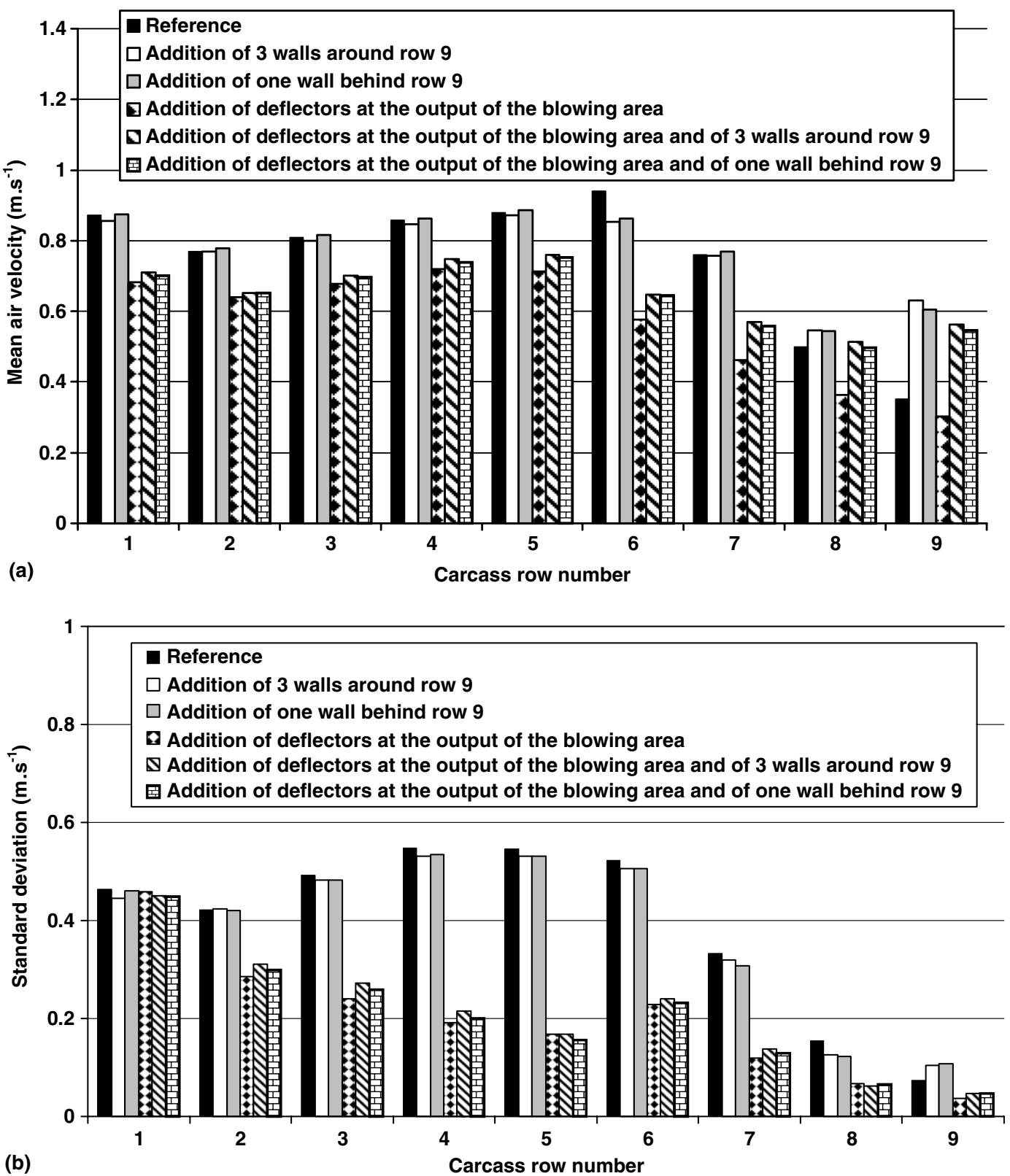

Fig. 8. Comparison of the numerical results obtained for five modified configurations of the chiller with the existing configuration taken as reference, in terms of (a) mean air velocity and (b) standard deviation of air velocity. 
before travelling towards the right and left corners of the industrial plant. Consequently, the ends of rows 6-9 seem to be more ventilated, in addition to the increased ventilation generated by the plastic walls surrounding row 9 which channel the airflow. Fig. 7 also shows that the presence of the post inside the chiller hinders the improvement of ventilation in the left corner, since the airflow blown towards the post is deflected on either side. This is a classic example of a plant that is badly designed in terms of airflow, where structural elements block the passage of the air.

The histograms giving the mean air velocities (Fig. 8a) and their standard deviation (Fig. 8b) versus each row of carcasses allow a clear assessment of the efficiency of adding the deflectors and the plastic walls. The values obtained in the case of the modified configurations of the chiller can be compared with the existing configuration taken as reference. Fig. 8 presents the CFD results for five modified configurations, in which one or three plastic walls were added in close proximity to row 9 , together with nine deflectors at the blowing area outlet with and without the plastic walls added. Analysis of Fig. 8a reveals that the installation of plastic walls mainly caused an increase in the ventilation level at row 9 , with mean air velocity increasing from less than $0.4 \mathrm{~m} \mathrm{~s}^{-1}$ in the case of the reference configuration to more than $0.6 \mathrm{~m} \mathrm{~s}^{-1}$ in the modified configuration. The numerical results remained the same whatever the number of plastic walls added. Moreover, by adding plastic walls only around row 9, no significant improvement was noticeable in the values of the standard deviation (Fig. 8b). On the other hand, the CFD models generated a marked decrease in standard deviation beyond the second row, together with a slight decrease of the mean air velocity onto rows $1-7$, following the addition of the set of deflectors at the air-conditioning system outlet. In view of the results presented in Fig. 8, combining added deflectors at the output of the blowing area with plastic walls added around the ninth row appears to be an efficient solution for evening out the ventilation levels throughout the length of each row of carcasses and between the different rows, while improving air velocity magnitude around the beef carcasses filling the last row. From a practical point of view, the solution consisting in adding the set of deflectors and only one plastic wall represents the best compromise between efficient gain in airflow patterns and investment costs. Furthermore, it also has the advantage of being simple to implement in an industrial configuration.

\subsection{Validation of the improvements numerically tested}

The best solution designed in response to the CFD investigation was effectively installed in the industrial batch-type carcass chiller. A second campaign of air velocity magnitude measurements was performed to assess the real efficiency of the CFD-designed technical modifications.

Fig. 9 gives a full comparison between the air velocities predicted by the CFD model and the measured values taken from the second campaign of experimental investigation. As in the case of the existing chiller configuration (Fig. 4a), the simulation results were in close agreement with the measured values; the slope of the straight line even reached 0.92 , compared to 0.86 previously. However, the coefficient $R^{2}$ decreased ( 0.72 compared to 0.81 ), revealing that the discrepancy between calculation and measurement has increased at several points, or possibly in certain areas of the chiller. Even so, the correlation between the predicted air velocities and the measured velocities remained clear. The air velocity measurements highlighted a slight decrease in mean air velocity magnitudes (about 10\%), but also a $67 \%$ decrease in mean standard deviations in the whole volume filled by the meat carcasses, thus con-



Fig. 9. Overall comparison of simulated and measured air velocities in the chiller configuration corresponding to the addition of a set of deflectors in front of the air-conditioning blower outlet coupled with only one plastic wall behind row 9 . 
firming the findings of the numerical modelling (Fig. 8). Several months after the experiment, the professionals using this batch-type chiller have unambiguously noted a marked reduction in the heterogeneity of the mean carcass temperatures on exit from the plant.

\section{Conclusion}

This study clearly shows that CFD techniques can be very useful tools for both assessing and improving air circulation in industrial meat carcass chillers, and thereby process efficiency, even though the representation of the filling of the plant was significantly simplified in the numerical models owing to the use of porous media. Following on from a first series of numerical models built to understand how the air flows in the existing configuration of the batch-type carcass chiller, a second series of calculations was performed in order to identify technical solutions for improving ventilation homogeneity in the plant. In general, comparison of calculations with measurements revealed close agreement in the predictions of air velocity magnitudes within the chiller.

The results reported here demonstrate that CFD is well suited to evaluating the significance and effects of modifying certain operating parameters or design elements on the performance of food processing apparatuses, and therefore to testing new technical improvement solutions at lowcost while saving time compared with an experimental investigation. Further progress can be expected in years to come as the CFD codes become more and more flexible while the calculating power of computers continues to increase.

\section{Acknowledgements}

The authors are grateful to INTERBEV and the OFIVAL for providing financial support for this project. We thank the employees of the study slaughterhouse for their friendly co-operation, and A.T.T. for re-reading the English version of this manuscript.

\section{References}

Anonymous (2001). Fluent 6: User's guide. Fluent Inc., Lebanon.

Bartzanas, T., Boulard, T., \& Kittas, C. (2002). Numerical simulation of the airflow and temperature distribution in a tunnel greenhouse equipped with insect-proof screen in the openings. Computers and Electronics in Agriculture, 34(1-3), 207-221.

Daudin, J. D., \& Van Gerwen, R. J. M. (1996). Air circulation: how to cope with this critical point? In J. D. Daudin (Ed.), New developments in meat refrigeration (1st ed.) (pp. 30-37). Utrecht: International Institute of Refrigeration.

Foster, A., Barrett, R., James, S. J., \& Swain, M. J. (2002). Measurement and prediction of air movement through doorways in refrigerated rooms. International Journal of Refrigeration, 25, 1102-1109.

Hirsch, C. (1988). Numerical computation of internal and external flows: computational methods for inviscid and viscous flows. Chichester: John Wiley and Sons Ltd.
Hoang, M. L., Verboven, P., De Baerdemaeker, J., \& Nicolaï, B. M. (2000). Analysis of air flow in a cold store by means of computational fluid dynamics. International Journal of Refrigeration, 23, 127-140.

Hu, Z., \& Sun, D. W. (2000). CFD simulation of heat and moisture transfer for predicting cooling rate and weight loss of cooked ham during air-blast chilling process. Journal of Food Engineering, 46(3), 189-198.

James, S. J., \& Bailey, C. (1989). Process design data for beef chilling. International Journal of Refrigeration, 12, 42-49.

Kondjoyan, A., \& Daudin, J. D. (1997a). Optimisation of air-flow conditions during the chilling and storage of carcasses and meat products. Journal of Food Engineering, 34, 243-258.

Kondjoyan, A., \& Daudin, J. D. (1997b). Heat and mass transfer coefficients at the surface of a pork hindquarter. Journal of Food Engineering, 32, 225-240.

Launder, B. E., \& Spalding, D. B. (1972). Mathematical models of turbulence. London: Academic Press Inc. Ltd.

Mariotti, M., Rech, G., \& Romagnoni, P. (1995). Numerical study of air distribution in a refrigerated room. In Proceedings of the 19th international congress of refrigeration (1st ed.) (pp. 98-105). Den Hague: International Institute of Refrigeration.

Mirade, P. S., Daudin, J. D., \& Arnaud, G. (1995). Simulation en deux dimensions de l'aéraulique de deux tunnels de réfrigération des viandes. Revue Internationale du Froid, 18(6), 403-412.

Mirade, P. S., \& Daudin, J. D. (1998a). Numerical simulation and validation of the air velocity field in a meat chiller. International Journal of Applied Science and Computations, 5(1), 11-24.

Mirade, P. S., \& Daudin, J. D. (1998b). A new experimental method for measuring and visualising air flow in large food plants. Journal of Food Engineering, 36, 31-49.

Mirade, P. S., \& Picgirard, L. (2001). Assessment of airflow patterns inside six industrial beef carcass chillers. International Journal of Food Science and Technology, 36, 463-475.

Mirade, P. S., Kondjoyan, A., \& Daudin, J. D. (2002). Three-dimensional CFD calculations for designing large food chillers. Computers and Electronics in Agriculture, 34, 67-88.

Mirade, P.-S., Agabriel, E., Brunet, Y., \& Boulard, T. (2004). Airflow modelling by computational fluid dynamics in an industrial plant filled with food products. In Proceedings of 9th international congress on engineering and food (1st ed.) (pp. 50-55). Montpellier: International Association for Engineering and Food.

Patankar, S. V., \& Spalding, D. B. (1972). A calculation procedure for heat, mass and momentum transfer in three-dimensional parabolic flows. International Journal of Heat and Mass Transfer, 15, 1787-1806.

Picgirard, L., \& Mirade, P. S. (2005). Validation de la simulation de l'aéraulique pour améliorer et/ou concevoir les ressuages de gros bovins. Viandes et Produits Carnés, 24(4), 131-136.

Scott, G. (1994). Computational fluid dynamics for the food industry. Food Technology International Europe, 49-51.

Scott, G., \& Richardson, P. (1997). The application of computational fluid dynamics in the food industry. Trends in Food Science and Technology, $8,119-124$

Van Gerwen, R. J. M., \& Van Oort, H. (1989). The use of fluid dynamics simulation models in cold store design. In Proceedings of commissions B2, C2, D1, D2/3 (1st ed.) (pp. 233-239). Dresden: International Institute of Refrigeration.

Wang, H., \& Touber, S. (1990). Distributed dynamic modelling of a refrigerated room. International Journal of Refrigeration, 13, 214-222.

Wooton, A. E. (1986). Factors affecting the chilling rate of beef sides. In Proceedings of commission C2 (1st ed.) (pp. 115-121). Bristol: International Institute of Refrigeration.

Xia, B., \& Sun, D. W. (2002). Applications of computational fluid dynamics (CFD) in the food industry: a review. Computers and Electronics in Agriculture, 34(1-3), 5-24.

Xie, J., Qu, X. H., Shi, J. Y., \& Sun, D. W. (2006). Effects of design parameters on flow and temperature fields of a cold store by CFD simulation. Journal of Food Engineering, 77(2), 355-363. 